\title{
An unusual presentation of a submucous leiomyoma accounting to a non-puerperal uterine inversion: A case report
}

\author{
Submüköz myoma bağlı uterusun inversiyonu: olgu sunumu
}

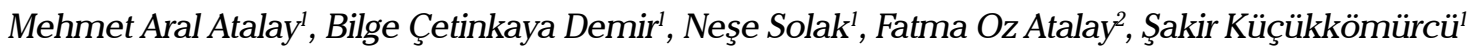 \\ 'Department of Obstetrics and Gynecology, School of Medicine, Uludağ University, Bursa, Turkey \\ ${ }^{2}$ Department of Surgical Pathology, School of Medicine, Uludağ University, Bursa, Turkey
}

\section{Abstract}

Non-puerperal uterine inversion is an extremely rare gynaecological
event that is usually associated with uterine tumours such as submu-
cous or cervical leiomyomas. In this report, we describe a case of
uterine inversion due to a large submucous leiomyoma in a 42 -year-
old multiparous and obese Caucasian woman. (J Turkish-German Gynecol Assoc 2013; 14: 116-8)

Key words: Leiomyoma, uterus, uterine inversion, vaginal hysterectomy

Received: 12 June, 2012

Accepted: 14 October, 2012

\section{Özet}

Gebelik ve lohusalıkla ilişkili olmayan uterin inversiyon oldukça nadir görülen bir jinekolojik durumdur. Genellikle submüköz veya servikal myomlar gibi uterin tümörlerin varlı̆̆ ile ilişkilidir. Bu yazıda, 42 yaşında, multipar, obez, Kafkas ırkından bir kadın hastada geniş bir submüköz myoma bağlı olarak gelişen uterin inversiyon tanımlanmaktadır. (J Turkish-German Gynecol Assoc 2013; 14: 116-8)

Anahtar kelimeler: Myom, uterus, uterin inversiyon, vajinal histerektomi

Geliş Tarihi: 12 Haziran 2012

Kabul Tarihi: 14 Ekim 2012

\section{Introduction}

Uterine inversion is a rare condition. Particularly, non-puerperal uterine inversion is a much more unusual event to encounter in a lifetime for a gynaecology specialist. It emerges particularly in an over-aged group of women of reproductive age. Uterine tumours and the use of hormone replacement are the main reasons specified in the literature; particularly, the presence of increased intra-abdominal pressure was considered to promote the occurrence of uterine inversion. It was previously indicated that systemic diseases, including chronic obstructive lung diseases, cardiac diseases, connective tissue diseases, and chronic inflammatory diseases like chronic inflammatory neuropathies, play a role in such processes. Likewise, morbid obesity was acknowledged as another facilitating factor.

\section{Case Report}

A 42-year-old, obese, multiparous woman of Caucasian origin was referred to our obstetrics and gynaecology outpatient clinic, with a main complaint of heavy menstrual bleeding. She had four vaginal births, resulting in 4 healthy children. Before admission, she had a history of multiple erythrocyte suspension transfusions on several occasions because of recurrent vaginal bleeding cycles in the last 2 years. In addition, she had been experiencing intermittent lower abdominal pain for the previous nine months. She did not describe any use of alcohol or cigarettes, and no hormonal medications were being taken. Also, she did not have a prior medical history of any systemic diseases, connective tissue diseases or chronic obstructive lung diseases. Unfortunately, the body mass index (BMI) of the patient was $34.48 \mathrm{~kg} / \mathrm{m}^{2}$. Gynaecologic examination revealed a large, pale, regular shaped mass measuring approximately $7 \mathrm{~cm}$ in diameter. The mass was found to dilate the cervix, and protrude through the cervix into the vagina. With detailed bimanual pelvic examination, the mass was interpreted as a prolapsed pedunculated submucous leiomyoma with a broad base. We were not successful in vaginal ultrasonography. Similarly, abdominopelvic ultrasonography yielded inconclusive results. Vaginal bleeding was not significant at this time. She was admitted to our clinic for further evaluation and any possible blood transfusion requirements.

Complete blood count (CBC) was evaluated. CBC showed anaemia $(\mathrm{Hb}=6.7 \mathrm{~g} / \mathrm{dL}$, and $\mathrm{Hct}=20.8 \%)$ due to chronic 
blood loss with a large number of newly formed erythrocyte precursors (red cell distribution width=18.5\%). Her vaginal bleeding increased moderately and descent of the mass was augmented in the first 24 hour period of her clinical follow-up. CBC was checked at 2-hour intervals. The mass totally prolapsed throughout vulvar introitus, and it became visible around the perineum upon a basic view. After a couple of hours, she showed signs of hypovolemic pre-shock comprising orthostatic hypotension and syncope following minor head raising, heavy sweating throughout the whole body, but particularly on the head and face, involuntary tremor in the extremities, and mild to moderate tachycardia and hypotension, but without apparent blood loss vaginally. At this time, $\mathrm{Hb}$ and Hct were measured as $5.5 \mathrm{~g} / \mathrm{dL}$ and $16.1 \%$, respectively. Transfusion with packed erythrocyte suspensions was started. At the same time, emergency surgery was planned comprising excision of the submucous leiomyoma transvaginally. Informed written consent was also taken from the patient in order to proceed for vaginal or abdominal hysterectomy. Gynaecologic examination under general anaesthesia revealed that the mass was not in fact pedunculated. The mass was fully palpated in the vagina, but no obvious demarcation line could be perceived between the mass, the apparent massive submucous leiomyoma, and the uterine cervix (Figure 1); the mass was coming out of all vaginal borders. We thought that the mass was composed of two parts encapsulating the distal and proximal parts. The leiomyoma, which was found within the vagina, composed the distal part, whereas the uterine corpus remained upwards in the pelvis. Dissection of the caudal part of the leiomyoma from its base through vaginal retraction was performed. We progressed through the procedure by dissecting, dividing and suturing the pedicles (Figure 1). After two steps of this surgical procedure, we were faced with a glossy surface on the inner layer of proximal part of the mass. We were convinced that this structure was the uterine serosa, but realised that the uterus inverted spontaneously, and that the uterus itself constituted the proximal part of the mass which was in continuation with the submucous leiomyoma with a broad base. A urethral catheter was then inserted and the procedure was performed as a conventional vaginal hysterectomy (Figure 2). The Foley catheter remained for two days and the patient was discharged without any complications.

\section{Discussion}

Non-puerperal inversion of the uterus is seen in extremely rare instances (1-3). The rate of misdiagnosis is higher than expected, as in our case. Mwinyoglee et al. reported in their review that $97 \%$ of the cases are associated with tumours, $20 \%$ of which were malignant (2).

The diagnostic value of transvaginal ultrasonography is limited, especially in cases with large masses protruding into the vagina. Principally, because of physical reasons one cannot administer the probe, as in this case, into a choked vagina. As another concern, ultrasound beams could not be transmitted beyond the mass, so technically one would gather poor quality sonographic images. Therefore, magnetic resonance imaging (MRI)

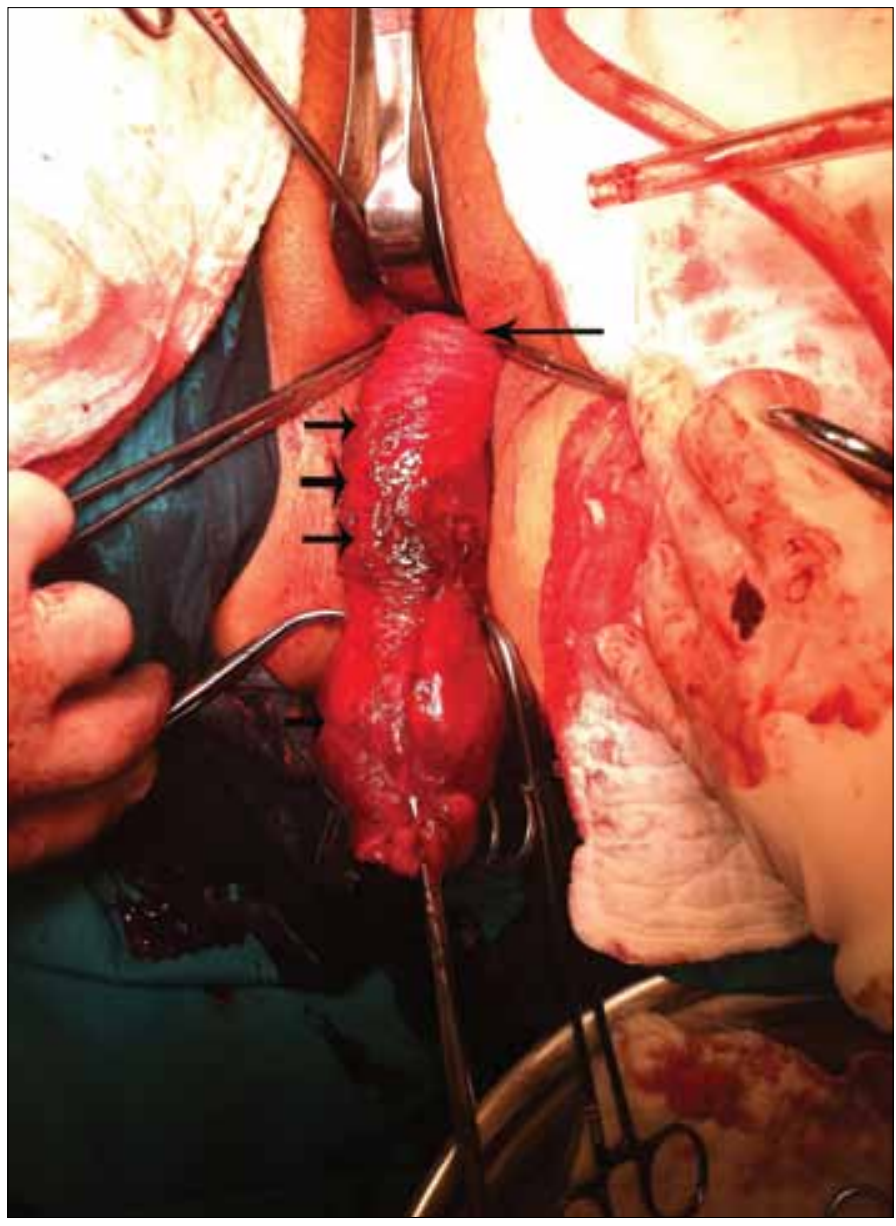

Figure 1. Intraoperative view of a hysterectomy which was performed transvaginally. The uterine serosa border is shown by a long arrow with a straight clamp at the top. Triple arrows show inverted uterine corpus. Short arrow indicates the submucous myoma, whereas curved clamps indicate the base of the tumour

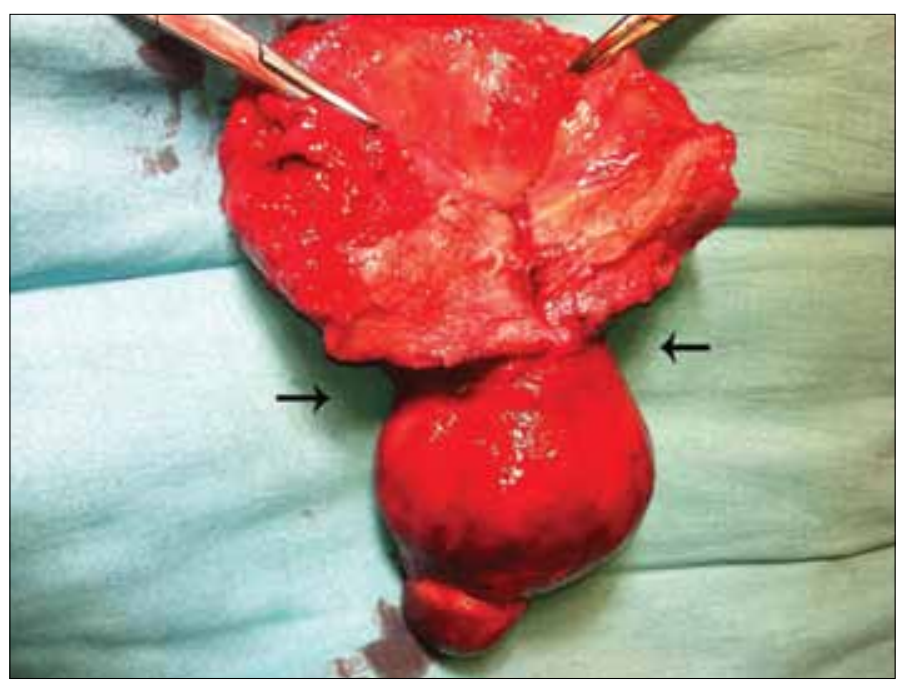

Figure 2. Postoperative picture of the submucous myoma within the uterus. Black arrows indicate the submucous myoma along with its broad base. Round ligaments which remained at the interior compartment are shown by straight clamps 
is the preferred diagnostic tool, and can provide an accurate diagnosis before surgery $(3,4)$. MRI can present the dimensions, and, more importantly, the extent of the tumour, and aids in the accurate diagnosis and treatment of the patient (4). We planned to get MRI sections in the case described; however we did not have time to perform the MRI because symptoms of vasovagal syncope and hypovolemic shock including hypotension, progressive pain and sweating emerged within the first 24-hours of the hospital stay. Non-palpation of uterine corpus on bimanual examination and non-visualisation of the uterine cervix after progressive excision of the vaginal mass as stated by Lascarides et al. gave clues for the correct diagnosis (5).

Reposition procedures, according to the reproductive desire of the patient, or hysterectomy could be considered for surgical treatment. Spinell and Kustner techniques are the two most accomplished organ-preserving vaginal approaches reported in the literature. In the Spinell procedure, an anterior longitudinal uterine incision is made after dissecting the bladder, while in the Kustner technique, the incision is performed in the posterior wall. After the incision is completed, both infundibulopelvic ligaments are clamped and ligated to prevent thromboembolic events, as suggested by Kopal et al. (6). Hysterectomy is the other alternative modality, and can be performed by both vaginal and abdominal routes. As uterine inversion is quite uncommon, most cases are misdiagnosed. In the case of a vaginallyprotruding mass, uterine inversion should be kept in mind as a differential diagnosis, particularly upon detection of submucous myomas larger than $4 \mathrm{~cm}$ in diameter. Once identified, vaginal hysterectomy could be chosen as a safe surgical modality. One should keep in mind that it is important to take biopsies from tumours before definitive surgery is planned because there is a $20 \%$ chance of missing the diagnosis of malignant tumours of the uterus or cervix. Also, adequate surgical management requires experience in vaginal surgery.

\section{Ethics Committee Approval: N/A}

Informed Consent: Written informed consent was obtained from the patient who participated in this study.

Peer-review: Externally peer reviewed.

Author contributions: Concept - M.A.A., B.Ç.D., Sु.K.; Design - M.A.A., N.S.., F.O.A.; Supervision - M.A.A., S..K.; Resource M.A.A., B.Ç.D., N.Sु., F.O.A.; Materials - M.A.A., F.O.A.; Data Collection\&/or Processing - M.A.A., B.Ç.D., N.Sु., F.O.A.; Analysis\&/or Interpretation - M.A.A., B.Ç.D., N.S., S..K.; Literature Search - M.A.A., B.Ç.D., Ş.K.; Writing - M.A.A., N.Sु., F.O.A.; Critical Reviews - M.A.A., Ş.K.

Conflict of Interest: No conflict of interest was declared by the authors.

Financial Disclosure: No financial disclosure was declared by the authors.

\section{References}

1. Pride GL, Shaffer RL. Nonpuerperal uterine inversion. Report of an unusual case. Obstet Gynecol 1977; 49: 361-4.

2. Mwinyoglee J, Simelela N, Marivate M. Nonpuerperal uterine inversions. A two case report and review of literature. Cent Afr J Med 1997; 43: 268-71.

3. Lewin JS, Bryan PJ. MR imaging of uterine inversion. J Comput Assist Tomogr 1989; 13; 357-9. [CrossRef]

4. Moulding F, Hawnaur JM. MRI of non-puerperal uterine inversion due to endometrial carcinoma. Clin Radiol 2004; 59: 534-7. [CrossRef]

5. Lascarides E, Cohen M. Surgical management of nonpuerperal inversion of the uterus. Obstet Gynecol 1968; 32: 376-81.

6. Kopal S, Seçkin NC, Turhan NO. Acute uterine inversion due to a growing submucous myoma in an elderly woman: case report. Eur J Obstet Gynecol Reprod Biol 2001; 99: 118-20. [CrossRef]

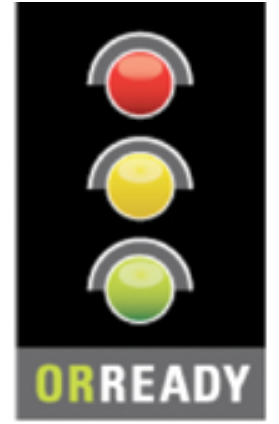

We are ORReady and support operating room safety to improve patient outcome.
ORReady is a worldwide, multi-Specialty initiative to encourage steps that are known to improve surgical outcomes and save lives.

If the suggested guidelines, which include Check Lists, Time Outs and Warm Ups are followed routinely, we estimate that Six Million patients around the world could have better outcomes.

Find out how your department and hospital can be ORReady and improve outcomes at http://www.sls.org/outcome 